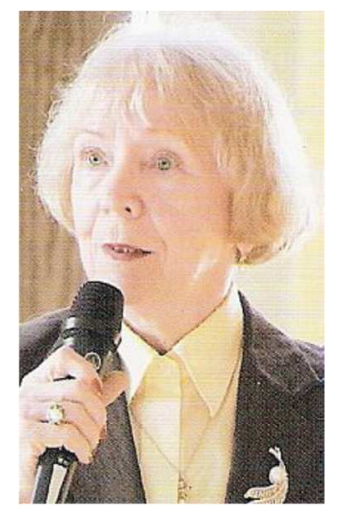

\title{
Gyöngyi Szabó Földesi as Scientist and University Teacher in Hungarian and International Perspective
}

Authors'contribution:

A) conception and design of the study

B) acquisition of data

C) analysis and interpretation of data

D) manuscript preparation

E) obtaining funding

\section{Gyöngyi Szabó Földesi ${ }^{1}$, Jerzy Kosiewicz ${ }^{2}$}

${ }^{1}$ Semmelweis University, Hungary

${ }^{2}$ Josef Pilsudski University of Physical Educationin Warsaw, Poland

\section{KEYWORDS}

This is the third article of the cycle of portraits of the members of the Editorial Board and Editorial Advisory Board of the journal Physical Culture and Sport. Studies and Research, who are eminent social scientists researching the issue of sport. Among them, there are many world-class professors, rectors and deans of excellent universities, founders, presidents and secretaries-general of continental and international scientific societies and editors of high-scoring journals related to social sciences focusing on sport. The journal Physical Culture and Sport. Studies and Research started its activities in 2008 and gathered many readers, distinguished authors and outstanding reviewers. It is worth taking a moment to present the profiles of the individual editors, thanks to whom the journal keeps getting better and better. The journal is increasingly appreciated internationally particular among the scientists from the humanist and social areas of investigations. The rapidly increasing number of its readers and its surprisingly wide reception, indicated by the number of visits and downloads in English-speaking countries, including hundreds of universities (up to 791 were interested in the content of issue 62 of our magazine), research institutes and related libraries, as well as academics, researchers and students, should be celebrated. These data are derived only from one bibliographic data base (EBSCO). It must be noted that the journal is indexed in 41 bases.

Education, academic achievements, scientific assumptions, publications

\section{The Third Portrait}

\section{Studies}

1961-1966 MA in Physical education, Hungarian College of Physical Education (HUPE), Budapest, 1973-1975 MA in Sociology, University of Eötvös Loránd, Budapest,

1979-1982 PhD in Sport sociology, Academia Wychowania Fizycnego, (Academy of Physical Education), Warsaw, Poland. 
State exams in languages: $\quad$ French (upper level), English (upper intermediate level), Russian (basic level).

Academic degrees University doctorate, ELTE (1976),

$\mathrm{PhD}$ in sociology (1982),

University doctorate, HUPE (1983),

Doctor of the Hungarian Academy of Sciences (2006).

\section{Work places}

1972 - College of Physical Education and its legal successor (Hungarian University and Physical Education, Semmelweis University Faculty of Physical Education and Sport Sciences and University of Physical Education) research worker, assistant professor, associate professor, and from 1988 full-professor.

\section{Administrative positions}

\begin{tabular}{|c|c|}
\hline 1984-1991 & Pro-rector for scientific affairs, HUPE, \\
\hline 1994-1991 & President of the Scientific Council, HUPE, \\
\hline 1984-1991 & President of the Doctoral Council, HUPE, \\
\hline 1999-1999 & Member of the Doctoral Council, HUPE, \\
\hline $1999-2005$ & President of Scientific Council, HUPE, \\
\hline $1999-2005$ & Member of the University Doctoral School Council, \\
\hline 2000-2007 & $\begin{array}{l}\text { Member of the Committee for Habilitation, President of the Sub Committe for Social } \\
\text { Sciences, 2007- Member in the Sub Committee for Social Sciences, }\end{array}$ \\
\hline 2000-2014 & Member of the Faculty Doctoral Council, \\
\hline $2000-$ & Member of the Sub Committee for Sport Sciences at the Hungarian Academy of Sciences, \\
\hline 2000-2001 & Member of the Doctoral Council at Semmelweis University, \\
\hline 2000-2014 & Head of PhD studies in social sciences, \\
\hline 2001-2008 & $\begin{array}{l}\text { Member of the Quality Control and Evaluation Board of the Doctoral Council at } \\
\text { Semmelweis University, }\end{array}$ \\
\hline 2008-2012 & Member of the Expert Committee in Sociology at the Hungarian Academy of Sciences, \\
\hline 2009-2012 & President of the Committee for University Textbooks, \\
\hline 2014- & $\begin{array}{l}\text { Member of the Doctoral School Committee, head of the Social Scientific program at the } \\
\text { University of Physical Education, }\end{array}$ \\
\hline 2014- & Member of the University Doctoral Council at the University of Physical Education, \\
\hline 2016- & Member of the University Ethical commission at the University of Physical Education, \\
\hline 2016- & $\begin{array}{l}\text { Head of the Social Scientific Sub-committee of the Habilitation Committee at the University } \\
\text { of Physical Education. }\end{array}$ \\
\hline
\end{tabular}

\section{Teaching activity}

1976- Sociology and sociology of sport at the HUPE, for PE the teachers, coaches, sports managers and human kinesiology majors, as well as at the postgraduate courses (in Hungarian and in English).

1981-1998 Supervisor of 12 doctoral students defended their thesis successfully (in Hungarian and in English),

1990-2004 Superviser of eight MA students who won prizes in the scientific conferences,

1993- Superviser of a doctoral student whose thesis won the grand prize in the category of social sciences awarded by the president of the International Olympic Committe,

1998- Superviser of $23 \mathrm{PhD}$ students defended their thesis successfully (in Hungarian and English),

2000- $\quad$ Supervising and lecturing at the University Doctoral School (in Hungarian and in English). 


\section{Guest professor}

1984 École Normal Supérieure d' Éducation Physique, Algír, Oran, Constantin,

1986 Panjab University, Chandigar,

1987 California State Polytechnic University, Pomona,

1988 California State Polytechnic University, Pomona,

1989 Charles University, Prága,

1994 WLRA International Centre of Excellence, Leewarden,

1995 Jyväskylä Egyetem, Jyväskylä (Doctoral school),

1996 University of Physical Education, Seoul,

1999 University of Lyon, Lyon (Doktori Iskola),

2000 UTAD University, Vila Real,

2002 AWF, Warsaw (Doctoral School),

2007 AWF, Warsaw (Doctoral School),

2008 INEF, Barcelona,

2009 AWF, Warsaw (Doctoral School).

\section{Invited lecturer}

1981 International Seminar of the International Committee of Sport Sociology, Halle,

1983 International Seminar of the International Committee of Sport Sociology, Paris,

1987 Scientific Conference on the Olympic East/West and South /North Cultural Exchange, Seoul,

1988 Scientific Olympic Congress, Seoul,

1989 International Seminar of the International Committee of Sport Sociology, Tallin,

1989 Conference on Human Right: Christians, Marxists and others in Dialogue, Washington,

1990 Congress International: "Deporte Para Todos": Aspectos Economicos, Victoria Gastiez,

1990 World Congress on Sport for All and Nutrition, Chicago,

1996 Scientific Conference on Sport for All organized by the International Olympic Committee, Seoul,

1997 Scientific Congress of the International Association of Physical Education for Girls and Women in Sports, Lahti,

1999 FISU Scientific Conference on University Sport, Peking,

2001 TAFISA Congress Conference on Sport for All, Cape Town,

2003 Asian Women Sport Conference, Doha,

2004 International Conference of the European Association for Sociology of Sport, Rzeszow

2004 Scientific Conference on University Sport, Bilbao,

2005 TAFISA World Congress, Warsaw,

2007 Scientific Conference on University Sport, Kaunas,

2009 FISU Scientific Conference, Harbin,

2009 ISSSS Conference, Warsaw,

2013 ISSSS Conference, Porto,

2014 ISSSS Conference, Kaunas.

\section{Participation in international research projects}

1978-1980 International project on sport socialization,

1985-1986 Polish-Hungarian study on sport-related values,

1987-1991 Cuban-Czech-Estonian-Polish-Hungarian comparative study on the population sporting values,

1987-1994 French-Hungarian survey on the use of time,

1994-1996 European study on racism and xenophobia on football,

2003-2006 Polish-Hungarian study on changing sports values in changing society,

2004-2006 European Union study on education through sport. 


\section{Major themes of scientific investigations}

\section{In the past}

- Sociological and Social-psychological Factors Influencing Performance of Athletic Teams; Investigation for the Objective Measurement of Cooperative Ability Among the Members of Sports Teams,

- Sport and Social Equalities; Social Status and Mobility of Elite Athletes; Changes in Social Status and Role of Top Athletes,

- Elite Sport, Social Norms and Values,

- The Health of Hungarian Olympians: A Sociological Approach,

- The Present and Future of the Olympic Movement,

- Sport, Life Style and Aging; Public Opinion of Physical Activity in the Later Years of Life Cycle,

- Social Role of Sports Events; Social and Demographic Characteristics of Hungarian Football-Fans and their Motivations for Attending Matches,

- Football, Racism and Xenophobia: Racist and Xenophobic Behaviour of Football-Spectators,

- Aggression and Violence in Sport from Sociological Perspective,

- Physical Culture in Social Consciousness,

- Sport and Gender; Traditional and Modern Myths in Female Sport,

- Sport and Legal Issues; Right to the Protection of the Human Body,

- University Sport from a Sociological Perspective,

- From Mass Sport to the "Sport for All" Movement in the Socialist Countries in Eastern Europe; Class or Mass: Sport for All Policy; Sport for All and New Political Reality in the Eastern European Countries,

- Sport and Tourism,

- Sport and Play for the Disabled,

- The Transformation of Sport in Eastern Europe; Post-transformational Trends in Hungarian Sport.

\section{At present}

- Social Exclusion/Inclusion in the Context of Sport,

- The Impact of the Global Economic Crisis,

- Sport in the European Union; Sport and European Integration,

- Assessing the Sociology of Sport.

\section{Memberships, offices in international scientific bodies}

1978- International Sociological Association, member,

1978- International Sociology of Sport Association, member,

1984-1991 International Association of Sport Sociology, vice president,

1992-1996 International Association of Sport Sociology, board member,

1998-2008 Hungarian Sociological Association, board member, and president of the Section for Sport Sociology,

1996- Hungarian Society for Sport Sciences, vice president,

1992-2015 Federation International des Sports Universitaire/Commission pour l'Etude du Sport Universitaire, commission member,

1994-2005 European Sport for All Academy, Scientific Committee, president,

2000-2006 European Association for Sport Sociology, board member. 


\section{Offices in editorial boards}

1984-1990 Scientific Review of the Hungarian University of Physical Education, president of the editorial board,

1986-1996 International Review for the Sociology of Sport (IRSS), co-editor,

1992-2008 Hungarian Review for Physical Education, member of the editorial board,

1995-1998 Journal of Comparative Physical Education and Sport, member of the editorial board,

1996-2000 IRSS, member of the advisory board,

1998-2012 Sportwissenschaft, member of the international advisory board,

2004-2010 Przeglad Naukowy Kultury Fizycznej, member of the advisory board,

2004- 2014 European Journal of Sport and Society, member of the editorial board,

2004-2010 Kalokagathia, member of the advisory board,

2008- International Quarterly of Sport Sience, member of the editorial board,

2009- Physical Culture and Sport. Studies and Research, member of the advisory board,

2009- 2012 Hungarian Review for Physical Education, editor-in-chief.

\section{Offices in sport}

1986-1991 Hungarian School Sport Federation, vice president,

1991-2012 Hungarian University Sports Federation, Executive Committee member, president of the Scientific Committe,

1998-2005 Trim and Fitness International Sport for All Association (TAFISA), vice president,

2002-2009 National Confederation of Hungarian Leisure Sports Federation, president,

2002-2007 Parliement Committee for Youth and Sport, member of the advisory board,

2004-2009 National Sport Council, member,

2007-2009 Parliement Committee for Sport and Tourism, member of the advisory board.

\section{Honours/ awards}

1977 First prize in individual category at a research competition at the Hungarian Academy of Sciences,

1983 First prize in group category at a research competition at the Hungarian Academy of Sciences,

1985 Award for Excellence by the Publishing House Közgazdasági és Jogi Könyvkiadó,

1984 Silver Juveline Award for the best sport book of the year,

1986 Award for Excellence by the Publishing House Sport Könyvkiadó,

1989 Hepp Ferenc Prize for excellence in sport science,

1995 Certficate of Merit by the National Office for Physical Education and Sport,

1996 Award for the best publication of the year by the Hungarian Sociological Association,

1997 Award for the best publication of the year by the Hungarian Sociological Association,

1997 „Master teacher” awards,

2006 Gold medal by the Hungarian Society for Sport Sciences,

2007 Order of Merit of the Hungarian Republic, Officer's Grand Cross,

2007 Gold medal for voluntary work in university sport,

2009 Life Work Award for serving university sport,

2009 Pro Universitate,

2010 Pro Facultate,

2009 International Society for the Social Sciences of Sport, honorary member,

2010 International Sociology of Sport Association, honorary member,

2012 Frenkl Robert Award,

2015 FISU Honorary Award,

2015 Jürgen Palm Award,

2016 Hungarian University Sport Federation, honorary member. 


\section{Publications}

In foreign languages (English, French, German, Polish, Russian, Czech, Bulgarian, Spanish): about 75 paper. In Hungarian: 7 books written plus 8 book edited, and more than 100 papers.

\section{Observations related to the portraits}

The presentation of the biography of a scientist (an academic teacher and, simultaneously, a researcher) is usually focused on:

1. Data concerning general and specialist education used (applied) during longstanding work.

2. Educational achievements referring to didactic and scientific supervision of graduated bachelors, MScs (MAs), and PhDs.

3. Scientific achievements connected with:

a) The area and directions of research, taking into account past, present, and prospective (planned) scientific activity, as well as individual, collective, national, and international achievements resulting from the realization of research projects, financed, e.g., by university, ministerial, or European grants;

b) The foundation of national and foreign scientific journals, performing the function of their editor-inchief and membership of their editorial teams;

c) The foundation of national and international scientific societies, performing the function of their chairperson and membership of their boards.

4. Three kinds of publications:

a) Those from the area of humanities and social sciences, taking into account, first of all, his/her own monographs, chapters in books, papers in journals awarded with high numbers of points, editorship of joint publications, and so on;

b) Publications concerning the natural sciences - distributed among its representatives - published mainly in journals with impact factor;

c) Handbooks and academic books serving academic teaching.

5. Professional issues connected with academic graduations, the attainment of degrees, and occupied posts and functions performed in national and foreign academic environments.

6. The effects of organizational activity connected with posts and functions performed in one or several academic environments, national or foreign. This refers, among other things, to the positions of rector and vice-rector, dean and vice-dean, head of doctoral studies, head of a department, unit, or work group, function of a chairperson and member of a senate or faculty commission - or of a commission connected with bachelor's or master's defenses or doctoral, habilitation, or professorship conferment procedures.

These biographies (CVs) are formulated in order to "give an outline" of the life and work of a given scientist and teacher in order to inform interested persons in a brief or broad manner about the scientist's academic achievements. This is a significant facilitator in reaching the audience and broadens knowledge about the effects of the scientist's activity in the discussed field, as nobody - without an important reason is going to spend time on toilsome and time-consuming inquiries in order to collect and organize data, which are usually numerous and contained in multiple sources, concerning the discussed field. Nota bene, PhD, habilitation, and professorship conferment procedures require the preparation of an appropriate $\mathrm{CV}$ whose content is checked by reviewers. The CV can be prepared in two significantly different versions, taking on an abbreviated or a broadened form.

a) The first is focused on objective factual and statistical data emphasizing the scientist's most important achievements. Facts are the most important element in this case, and they should be deliberately free of subjective commentaries by the author.

b) In contrast to the first version, the second version may have monographic overtones and includes a narration describing and explaining the course of a given person's academic career, the journey to his or her current place in the academic world. It also points out - more or less openly - prospects of future creative development and includes data - formulated more or less implicitly - about the 
personality, needs, and predispositions underlying the achieved results. Through this, we can learn more about a given person's scientific, didactic, and educational preferences, his/her method for establishing international relations and their range, and the line-up, range, and aims of smaller or bigger national or international research teams.

The choice of one of the abovementioned versions depends solely on the given scientist. The Editorial Board fosters any kind of self-presentation, and it recommends each text to all those who deal with sport social sciences: both to readers and to colleagues from the Editorial Board.

The main aims and motivations for preparing CVs of the abovementioned research workers are, among others:

a) Existing competitions for professional positions: in Poland, for example, for research assistant, senior research assistant, lecturer, senior lecturer, assistant professor, associate professor, or full professor positions;

b)Elections for academic positions: in Poland, for example, for those of the position of rector, vicerector, dean, or vice-dean;

c) Solicitations connected with receiving scientific degrees, such as those of a doctor, habilitated doctor, or professor (which is granted for life);

d)Elections for national and foreign scientific organizations and societies;

e) Solicitations connected with granting a distinction and degree called Doctor Honoris Causa of a given university at home or abroad.

We are also of the opinion that scientific journals should present the works and achievements of their editors and members of their editorial boards. Admittedly, information concerning affiliation is commonly published and is necessary for formal reasons. However, it often takes a form that is too rudimentary. This is the reason why the Editorial Board of Physical Culture and Sport. Studies and Research has decided to present the profiles and achievements of its members more broadly. Doing so performs three important functions:

a) It justifies their presence on the editorial team;

b) It valorizes the journal in scientific terms;

c) It provides information about who - besides reviewers - is concerned that the published texts are of the highest quality.

All of the CVs prepared by the concerned person for readers from the environment and from external sources are a particular self-presentation, and they rightly have a somewhat self-laudatory or cryptolaudatory character. Those who want to present their own achievements should not - as we suppose - present them in a bad light.

The assumptions and conventions of a biography - which sums up, e.g., overall university activity require, first of all, a true and fair presentation and possibly characteristics of real successes and significant achievements. The author's weaknesses, shortcomings, and deficits are rather not pointed out in these kinds of statements. The presented data and possible commentaries by the author must, however - and this is an indispensable and necessary condition - always be transparent and testable, i.e., verifiable.

Even in the most abbreviated, semantically ascetic self-presentations oriented towards extreme objectivity, free of contextual explanations and interpretations, focused solely on the presentation of bare facts, self-laudatory elements and preferences may appear. This can be proven by, for example, the selection, number, or structure of gathered data concerning national and international achievements. If we are discussing a distinguished person, his/her self-presentation usually elicits recognition and respect. Unfortunately, the environment may transform these into feelings of jealousy and jaundice.

The abovementioned emotions in the environment, that is, a "genetic" lack of goodwill towards outstanding figures, sometimes lead to a deliberate deforming and diminishing of the significance and value of their achievements - for example, in the form of "confidential" dissemination and perpetuation of false data concerning a given person's works and personality.

In this case, one of the possibilities for breaking a tightening noose of lies is the publication of transparent (and, of course, testable) data about the research and the academic worker's real achievements. 
The dissemination of unfair and deliberately false messages comes upon a breeding ground when the scholar, motivated by exaggerated modesty (referring somehow to Pythagorean anonymity connected with mathematical and astronomical discoveries), does not provide information about his/her more or less extensive corpus. We do not recommend such an attitude - it enhances the appearance of doubts or disinformation.

An academic and research worker should successively modify the data concerning his/her current achievements and popularize them in his/her closer or broader professional environment.

The lack of such popularization causes, among other things, people from his/her research environments, both national and international ones (closely cooperating and allegedly well-informed), to be unable to formulate even a minute-long solid announcement concerning, for example, a keynote speaker, the organizer of a conference, or the chairperson of an association. This refers, among other things, to situations that happened during the last conferences of the International Sport Social Sciences Society and the Polish Sport Social Sciences Society. Unfortunately, the announcers did not know what to say. Their statements included surprising mistakes.

And this is worth preventing.

AUTHOR'S ADDRESS: $\quad$ Gyöngyi Szabó Földesi

Semmelweis University

Faculty of Physical Education and Sport Sciences

Alkotás utca 44 1123, Budapest

Hungary

E-mail: foldesi@tf.hu

Received: 20 January 2016; Accepted: 16 March 2017 